\title{
A marine spatial data infrastructure in New Zealand: a systematic review on the cost-benefits
}

Word count: 5,600

Abstract: National Spatial Data Infrastructures (NSDIs) underpin a diverse range of activities that contribute to the development of a country. Considering the major investment that has gone into developing NSDIs, most focus on terrestrial-based rather than marine-based spatial data.

Using New Zealand as a case study this paper presents a review of international studies that use costbenefit analysis to estimate the economic effects of MSDIs.

Cost-benefit ratios for investing in MSDIs range between 1:2 and 1:18. The results suggest that MSDIs are cost-effective activities and integral to realising the full economic potential of the marine environment.

Benefits arise from efficiency of data collection, improved risk assessment for navigation, more effective marine spatial planning, supporting of marine science, reduced mineral exploration costs and disaster management.

The research provides evidence for investing into an MSDI in New Zealand and stimulates debate on the varying methods underpinning economic studies in the marine geospatial context.

Keywords: Marine Spatial Data Infrastructure, Hydrography, Geospatial 


\section{Introduction}

The ocean is an important asset to coastal and island economies. It is estimated that in 2014 gross marine product (GMP) was at least US\$2.5 trillion or approximately $3 \%$ of global GDP (US\$77.9 trillion) (Hoegh-Guldberg 2015). ${ }^{1}$

In 2013 the New Zealand marine economy directly contributed \$4 billion (1.9\% of total GDP) towards the total economy, with offshore minerals (48\%), Shipping (24\%) and fisheries and aquaculture (22\%) making up the largest contributions (Statistics New Zealand 2016).

Over the next 10-30 years, there will be substantial development and growth in New Zealand's marine economy. For example, it has been estimated that the development of oil and gas could generate an additional $\$ 1.5$ billion of export revenue in an average year of production over 30 years and an additional $\$ 300$ million per annum in taxes for the government (NZ Institute of Economic Research 2012).

Marine spatial data is a key component that will sustain and enable the growth of the marine economy. Geographical Information (GI) or spatial data can support better decision-making and as a consequence can contribute to the economic development of a nation. For example, a recent 2015 meta-analysis on the return on investment (Rol) of geospatial data and systems estimated the expected benefits of $\mathrm{Gl}$ investments to be approximately 3.2 times larger than the costs (Trapp et al 2015).

Access to marine spatial data can be achieved through a Marine Spatial Data Infrastructure (MSDI). An MSDI is often considered as the marine component of a National Spatial Data Infrastructure (NSDI) i.e. a collection of technologies, policies, institutional arrangements and people necessary to facilitate the availability of, and access to, spatial data (Open Geospatial Consortium (OGC) 2015). So in its widest sense an MSDI is:

the component of an SDI that encompasses marine geographic and business information, which typically includes seabed topography (bathymetry), geology, marine infrastructure (for example wrecks, offshore installations, pipelines and cables), administrative and legal boundaries, and areas of conservation, marine habitats and oceanography (International Hydrographic Organization 2011a).

MSDIs are increasingly being developed and used to deliver a wide range of data to those who make decisions on the marine environment. Historically, marine spatial data, including depth, was collected and used by hydrographers to produce nautical charts to aid navigation. However, over the last 30 years marine spatial data has been collected by a growing number of different groups, and is now being used for a wide range of applications, many of which require highly detailed and accurate data. For example, in addition to navigation, marine spatial data is used to support activities such as coastal zone management, exploration and exploitation of marine resources, environmental protection and maritime defence (International Hydrographic Organization 2011b). For example, it has been argued that 'there is a growing and urgent need to create a seamless SDI model that bridges the gap between

\footnotetext{
${ }^{1} \mathrm{GMP}$ is equivalent to a country's annual GDP
} 
the terrestrial and marine environments' (Vaez et al 2009), for the preservation, sustainable management and development of the coastal zone.

This increase in use of marine spatial data has been attributed to the United Nations Convention on the Law of the Sea (UNCLOS) (United Nations 1982) and the greater definition of coastal state boundaries that UNCLOS has provided (Fowler, Smith and Stein 2010), coupled with the development of information and communication technology (ICT) and the ability to exchange and share data and information.

NSDIs are well developed globally; however, many just focus on terrestrial-based spatial data and rarely incorporate a marine spatial data component (Fowler et al 2005, Strain et al 2006). For many nations, the collection and use of data in the marine sector is still in an uncoordinated state (Gajewski et al 2012). This leads to duplication of effort, poor information for decision making and lost opportunities. Hence, the lack of investment into a formal MSDI could be hampering achieving the true value of marine spatial data.

The lack of investment in an MSDI is no less the case in New Zealand. Whilst marine data is recognised as part of the NSDI and fundamental to assisting in national economic development, it has thus far not been the focus (Australia New Zealand Land Information Council (ANZLIC) 1996, p. 11, LINZ New Zealand SDI State of Play Report, 2012).

Several attempts have been made to develop an MSDI in New Zealand but none have succeeded. One example is Oceans Survey 20/20, which was a proposal to use a federated approach to marine data management. Even so, in 2015 an investigation found little coordination of effort in New Zealand to streamline the acquisition and dissemination of marine data (LINZ 2015) and re-iterated that an MSDI had not been created.

One reason for the overall disinterest in a New Zealand MSDI may be a lack of comprehensive evidence on their social and economic benefits. First, whilst there are studies that compare costs and benefits, there is no published literature that provides an objective view of all of these. Second, many of the good examples of MSDIs do not have publically available cost-benefit details. Lastly, many studies on MSDIs do not undertake original cost-benefit analyses or justify the benefits of MSDIs through qualitative benefits. For example, many case studies conclude that marine data will improve decisionmaking but do not quantify the down-stream social and economic benefits.

The aim of this paper is to collate and review the main economic studies across the globe in the MSDI field. This is in attempt to address the gap in the literature highlighted above and provide a holistic view on the costs and benefits of MSDIs. Specifically the paper will break down the differences between each of the studies and provide a view on the degree to which MSDIs are economically beneficial. It is the intention that this paper provides evidence for countries wishing to develop MSDIs.

The structure of this paper is as follows. First we present our approach and methods for identifying and reviewing the available literature. We then provide a commentary on the results of the literature search and the overall aggregated results of the review. We then discuss, compare and contrast the results in terms of literature focused on national hydrographic services, because these are typically the largest collectors of marine information, mainly bathymetry; coastal mapping programmes, often holistic blends of hydrographic services and data portals; and lastly literature specifically on the 
benefits of the marine spatial data provision. Lastly we discuss these results in context to the implications for an MSDI for New Zealand.

\section{Methods}

In this study we use a qualitative approach to review the costs and benefits of implementing an MSDI. We provide descriptive statistics for the studies we have identified and then qualitatively compare and contrast common themes in the discussion part of this paper. This approach differs from a traditional meta-analyses and systematic reviews that employ statistical techniques to combine the results of many clinical trial studies, the idea being that combining results increases their power and certainty. There are currently no agreed upon methods for combining estimates of cost-benefit ratios (The Cochrane Collaboration 2011) and therefore we do not seek to undertake a traditional metaanalysis here.

To gather studies for the review, CiteUlike, Research Gate and Google Scholar were used as the primary search engines to search for relevant literature. First a broad search was completed using combinations of the terms 'hydrographic services review', 'benefit/cost', 'data provision', 'marine' 'spatial data infrastructures' and 'marine data portal'. Next, to supplement the automated search, a manual search was completed using references from relevant literature. The first useful review of the benefits and costs of hydrographic data was conducted in Canada in 1992. Therefore we included studies dated from the 1990 s onwards.

Our review includes scientific articles both peer-reviewed and non-peer-reviewed and reports published up to 2015. Each article found in the search was reviewed by the authors. We accepted papers and reports that had a spatial data provision component as well as an original and quantitative cost-benefit analysis. It was also highly desired that papers or reports had a specific focus on marine data. We have also included cost-benefit analyses that look at hydrographic services and have an MSDI component in them. This is because of the important role that hydrographic services play in developing and supporting MSDIs. Table 1 shows the identified study papers that complied with our inclusion criteria.

Table 1: study papers complying with our inclusion criteria

To make sure costs and benefits were comparable; the costs and benefits for each of the studies were first converted from their currencies into US dollars at the time of the study. Then, US dollars were then converted into 2015 US Dollar values (the latest study published). Lastly a ratio was created from the costs and benefits. Four studies had both low and high cost-benefit ratios. Both ratios are reported and statistics which incorporate each set of ratios are provided.

Studies that had extreme outliers were excluded. To detect these we produced an average ratio and excluded any studies that had ratios outside two standard deviations from the mean. We excluded the Vanuatu case study, which reports an ROI of between 1:91 and 1:268 over six years (Secretariat of the Pacific Community 2014). Vanuatu, like many other pacific nations, has a very unusual set of circumstances which could support this figure, i.e. little or no hydrographic services. For example, the net gains of going from not having a hydrographic service to having one are huge because no existing benefits have been realised. The net gains of improving an existing service are much smaller, because many benefits have already been realised. 
The remaining eight studies were classified into three areas that emerged from the literature:

National hydrographic services: typically the largest collectors of marine information, mainly bathymetry.

Coastal mapping programmes: often a blend of hydrographic services that collect data and data portals to serve it up.

Marine spatial data provision: literature on the benefits of the marine spatial data provision through geoportals (not restricted to data collected by hydrographic authorities).

\section{Results}

\section{Cost-benefit methods identified}

In the reviewed literature two methods were most commonly used to measure costs and benefits; cost-effectiveness analysis (CEA) and cost-benefit analysis (CBA) (Cellini and Kee 2010, p. 493).

Cost-effectiveness analysis (CEA) seeks to identify and place dollars on the costs of a program. It then relates these costs to specific measures of program effectiveness. The cost-effectiveness (CE) ratio is expressed as:

$$
\mathrm{CE}=(\text { Total cost }) /(\text { Units of effectiveness })^{2}
$$

CBA goes beyond CEA and attempts to compare costs with the monetary value of all (or most) of a program's benefits, expressed as:

$$
\text { Net Benefits }=\text { Total Benefits }- \text { Total Cost }
$$

CEA is usefully employed when you know the outcome you desire and are determining which set of programmes or options achieves the greatest outcome for costs. CBA is most useful when you are analysing a single programme or policy to determine whether the program's total benefits to society exceed the costs (Cellini and Kee 2010, p. 493).

Many studies employing CBA will often use 'with' and 'without' scenarios to quantify the benefits. This is not a true counterfactual analysis, which is a comparison between what actually happened and what would have happened in the absence of the intervention, but the analysis of two hypothetical situations.

\section{Descriptive statistics}

All the studies we reviewed showed a net economic benefit from investing in MSDIs, with an observed cost-benefit ratio between 1:2 and 1:18. So for every $\$ 1$ invested into the development of an MSDI, you would expect to receive between $\$ 2$ and $\$ 18$ back in economic benefits. Figure 1 compares each studies costs versus benefits (standardised to USD) and Rol. The y axis shows the cost of each initiative in US dollars on a logarithmic scale. The $X$ axis shows the benefits of each initiative in US dollars on a

\footnotetext{
${ }^{2}$ Where 'Units of effectiveness' are a measure of any quantifiable outcomes central to the program's objectives.
} 
logarithmic scale. The size of each bubble represents the proportion of the benefits compared with costs.

Figure 1: Studies reviewed costs versus benefits (standardised to USD)

The graph shows a clear outlier with the Eurpoean/EMODnet initiative as it has considerably higher costs and benefits and an overall cost-benefit ratio of 1:18; the next highest before that being a ratio of $1: 9$.

For the eight studies we included in the analysis when low estimates were included the minimum ROI was 1:2 and the maximum was 1:18, the mean ROI was 1:7, with a standard deviation of 5 and a standard error of 1.8. When we included high estimates the minimum ROI was $1: 2$ and the maximum was 1:56, the mean ROI was 1:13, with a standard deviation of 17.8 and a standard error of 6.3 . The inclusion of low ROIs represents a better picture of the actual cost-benefits.

Table 2 provides an overview of the literature reviewed. The table provides the title of the literature, the country of analysis, and which of the three areas (detailed above) it is classified as. The 'analysis method' column provides information on which of the two methods outlined above was used. The 'costs included' column represents the costs of activities that are being analysed. The 'quantified benefits' column represents the benefits that are being measured against the activities. The 'unquantified benefits' are any benefits that are included, but not quantified. The 'year' column indicates the date the work was published. The 'project period' column indicates the timeframe during which the project or programme runs and costs are allocated for. The 'costs (000s)' and the 'benefits (000s)' columns show the total quantified cost and total quantified benefits in cost in thousands, in the currency indicated in the work. Lastly, the 'ratio' column shows a simple ratio between the costs and the benefits. Where there is an upper and lower cost-benefit bound, this is shown alongside a respective ratio.

Table 2: overview of the literature reviewed

\section{Discussion}

This section discusses the overall results and reviews the eight studies identified above in their context to national hydrographic services, coastal mapping programmes and marine spatial data provision. Each study is reviewed separately and then compared with the other studies in their respective areas.

\section{Overall Cost and benefits of MSDIs}

As demonstrated in Figure 1, all the studies we reviewed concluded that MSDIs were economically beneficial to some degree, from a minimum return of 1:2 (i.e. two dollars return from every one put in) to and maximum of 1:18.

The differences in return reflect both the different sizes of each programme but also the multitude of ways to measure and quantify costs and benefits. Half of the studies used CBA to measure the costbenefits and half used CEA. In particular what's included or excluded from the programmes costs and benefits varies considerably and influences the overall results of each study. For example, quantified costs can be attributed to three distinct areas: data collection/acquisition, data management and analysis. Many studies do not include all of these areas but only one or two of them. In terms of 
benefits these vary considerably and often are non-specific. However benefits can be classed into general commercial benefits, such as increased productivity in the fishing sector, more efficient commercial shipping, time and money savings in data collection, for example reduction in duplication and softer benefits such as better research and decision making, for example reduction in uncertainty. Often the pure MSDI focused studies concentrate on the softer less tangible benefits such as better research and decision making whilst the hydrographical focused studies concentrate on commercial benefits.

\section{National and regional hydrographic services}

Hydrographic services gather reliable and up-to-date information vital for charts and safe navigation. Recently it has been recognised that hydrographic information goes beyond the traditional mariner and is relevant for a range of other groups and activities (International Hydrographic Organization 2011a, Connon and Nairn 2010). For example government agencies, coastal managers, engineers, and scientists can use hydrographic data to benefit activities such as tourism, commercial shipping, fishing, scientific research and coastal zone management.

Hydrographic services can make this data available through an MSDI. Many hydrographic services are already involved in developing marine SDIs, for example Australia, the USA (National Oceanic and Atmospheric Administration (NOAA)), and Canada all have MSDIs run by their national hydrographic services. In this respect, hydrographic services play a significant role in the development of SDIs (International Hydrographic Organization 2011b).

Reference is made to three studies in this section: 'Benefit-cost assessment of the Canadian Hydrographic Service', 'The cost-benefit of charting Cameroon waters', and 'Analysis of the economic benefits of the provision of hydrographic services in the APEC region' (APEC (Asia-Pacific Economic Cooperation) being the hydrographic services of 21 Pacific rim economies, of which New Zealand is a member).

The costs-benefit outcomes vary considerably between the three studies. However, all show hydrographic programmes to be cost-effective in terms of the economic benefits. For example the 'Benefit-cost assessment of the Canadian Hydrographic Services' reported a return on investment OI) of 1:9 over 15 years (Brinkman and Caverley 1992), whilst a review on hydrographic services in the APEC regions reported an ROI of 1:3 over 25 years (Transportation Working Group 2012).

Overall, the difference in ROI between studies is due to variations in cost-benefit methods and frameworks applied (including the discounting factor employed), and differences in scope e.g. which costs and benefits have been included or excluded. All the hydrographic service reviews use the counterfactual argument to look at cost-benefits. 'With' or 'without' scenarios determine the impact of hydrographic services on various activities. However, the type and number of activities included varies between each study and is often the differing factor. For example, many include additional benefits of hydrographic data to activities such as tourism, mineral exploration, commercial fishing, etc.

Three consistent themes relate to MSDIs throughout the national and regional hydrographic service reviews: 
Data collected by hydrographic services can be re-used for many more purposes than just producing and maintaining nautical charts.

An important aspect of hydrographic services and associated mapping programmes in the context of economic benefits is recognising that parts of them are public goods, i.e. they are non-excludable and non-rivalrous. The public good argument has important implications for marine data in New Zealand in terms of the ability to use data generated by public organisations for multiple purposes without inhibiting its original intended use.

Collective action is an important concept for the collection of marine data. Collective action is the term used to describe an action taken together by a group of people to achieve a common goal. In terms of marine data collection it is cheaper and more efficient to collect data once, rather than multiple times by different organisations.

In summary the three studies reviewed in this section recognise that there are multiple uses for the marine data collected via hydrographic services. However, the studies do not go beyond identifying the importance of marine data, for example by recommending the establishment an MSDI.

\section{Coastal mapping/monitoring programmes}

Coastal mapping and monitoring programmes integrate the collection and dissemination of marine data (primarily bathymetry and geophysical data), with the philosophy of 'map once, use many times' (NOAA 2015).

Two reviews directly measure the cost-benefit of coordinating the collection and delivery of marine data through coastal mapping or monitoring programmes: 'Marine mapping study options appraisal report: final report' (INFOMAR 2008) and England's 'Review of the Strategic Regional Coastal Monitoring Programme' (Bradbury 2006).

\section{INFOMAR}

INFOMAR's objective is to completely map Ireland's offshore waters and to create a range of integrated mapping products of the physical, chemical and biological features of the seabed. The programme includes data acquisition, data management and interpretation (for example the production of a range of information products such as bathymetric/water depth maps) and data exchange (INFOMAR 2008). The total cost of the project is estimated to be $€ 70$ million, with $€ 3.8$ million of this being allocated to data management. In terms of data management, it is expected that establishing an SDI and a national marine data discovery and exchange service could yield benefits over a 10 year period of between $€ 2$ million and $€ 16$ million (INFOMAR 2008, p. 6). Suggested benefits include improved dissemination of information to policy makers, shared-cost approaches, and reduction of duplication of effort. It is estimated that the project has already leveraged earnings of $€ 5$ million for leading-edge Irish research institutions and organisations associated with integrated seabed mapping and geosciences (PWC 2008, p. 23). Furthermore, the database had been utilised in a number of other areas such as the national wrecks database, habitat mapping, hydrographic charting and selecting sites of conservation.

England's Strategic Regional Coastal Monitoring Programme 
In comparison, England's Strategic Regional Coastal Monitoring Programme aims to coordinate and integrate coastal monitoring to maximise use of data and provide the greatest value for money. Included within the programme is the monitoring and analysis of marine data and its provision to the public. With an investment of $£ 6.3$ million over five years, and a proportion of that going towards building and maintaining a geoportal, the programme is expected to deliver benefits in the range of between $£ 4.3$ and $£ 19.3$ million. Specific short-term benefits (year 1 ) would come from time savings in data collection, preservation of data, efficiency of data collection and procurement efficiency (Bradbury 2006).

Both the INFOMAR and English Strategic Regional Coastal Monitoring Programme studies use appraisal of options to measure costs and benefits and both include aspects of delivering data through geoportals and include costs and benefits associated with this activity. For example, data acquisition and also data management (storage and distribution) both feature as costs. The two studies differ in the quantified benefits with INFOMAR focusing on broader marine specific benefits such as 'improved commercial fishing', and English Strategic Regional Coastal Monitoring Programme identifying more generic benefits related to data such as 'time-savings in data collection' or 'reducing duplication of data'.

\section{Marine spatial data provision through geoportals}

Provision of marine data through data portals are by definition MSDIs. The Infrastructure for Spatial Information in the European Community (INSPIRE), the European Marine Observation and Data Network (EMODnet) and Digital Coast all collect data from multiple places and make it available through a single source.

\section{INSPIRE}

In Europe, spending on collecting and processing marine data is upwards of $€ 1$ billion for public bodies and $€ 3$ billion for private entities (European Commission 2010, p. 11). For this reason, marine data has been identified as an important asset in Europe. The INSPIRE directive, which lays down a legal framework for an SDI, has compelled European countries to develop geoportals to serve their marine datasets (European Commission 2007). There are currently a number of geoportals specifically funded to manage and distribute marine data, although cost-benefit information for these is not available. However, an extended evaluation of the cost-benefits of the wider INSPIRE programme, not explicitly focusing on the marine domain, found the benefits to outweigh the costs by a ratio between 1:6 and $1: 12$. The study sets out five options that concentrate on the policy of managing and sharing geospatial data, ranging from doing nothing to creating EU legislation stipulating how member states should implement INSPIRE. It concluded that the main benefits of the programme were the reduction of the duplication of data collection, improved decision-making and more cost-effective expenditure (Dufourmont 2004).

\section{EMODnet}

EMODnet aims to provide free access to, and use of, European marine data across seven disciplines (bathymetry, geology, seabed habitats, chemistry, biology, physics and human activities). The 2010 EMODnet impact assessment considers the economic impact of marine data provision and sets out three options (each one additive to the last). The first option concentrates on assembling the data to 
provide comprehensive access to it, the second looks at supporting observation systems and the collection of data, and the third deals with applying the data to provide environmental indicators such as the level of coastal erosion.

The assessment identifies that the reduction of operational costs and delays for those who use marine data will help the private industry to compete in the global economy, improve the quality of public decision-making at all levels and strengthen marine scientific research. The assessment reports that a reduction in the uncertainty of knowledge of the oceans and the seas will provide a basis for managing inevitable future changes. For example the implementation of EMODnet could reduce the level of uncertainty in future sea-level rise and may save as up to $€ 100$ million per year in sea defences (European Commission 2010). It is also argued that an integrated marine observing system could reduce costs to those who deliver products and services by $25 \%$.

\section{Digital Coast, National Oceanic and Atmospheric Administration (NOAA)}

More recently, NOAA has quantified the benefits and costs of Digital Coast, a data portal developed by NOAA, which provides marine data to help US communities address coastal issues (NOAA 2015). In the Digital Coast focuses on assessing the benefits to the whole nation, including government agencies, non-governmental organisations, researchers and the private sector. The study addresses the question 'is the [USA] nation better off because of the investments in the Digital Coast and, if so, how much better off?'

Overall the study found that Digital Coast produced benefits in the tune of US\$30 million over seven years, compared to just US\$7 million in costs (NOAA 2015).

In particular the study identified two primary classes of benefits:

Improved efficiency by way of reduced labour costs needed to find, prepare, obtain and use trusted products and services, and

Increased effectiveness because using products and services from Digital Coast leads to better decision making and improved coast management outcomes.

The study concluded that, 'there is a high degree of confidence [that benefits] greatly exceed the anticipated future costs for the Digital Coast' (NOAA 2015, p1).

The INSPIRE and EMODnet studies use appraisal of options to measure costs and benefits i.e. CEA whilst the Digital Coast study uses the counterfactual i.e. CBA. Although all three studies are very different in what they include in the costs, their quantified benefits do have some common themes, for example efficiency gains from the reduced duplication of data collection. Furthermore at the lower end of their estimates each study reports consistent cost/benefit ratios of between 1:4 and 1:6 over periods between seven and ten years.

\section{Implications for MSDIs in New Zealand}

The New Zealand marine economy is a major contributor to the total economy and is predicted to grow over the next 10-30 years. In Auckland alone the recreation marine industry is forecast to increase its turnover from 1.2 billion in 2008 to 1.8 billion by 2020 (Barbera 2012). Marine data is a key component that will help this growth. Developments which use spatial data such as the marine 
spatial plan for the Hauraki Gulf Marine Park, have already demonstrated the power of federated marine spatial data, however these programmes could be replicated across the nation. In relation to the studies reviewed in this paper and the positive benefits they demonstrate, the lack of an MSDI in New Zealand may be causing data deficiencies, and in turn be effecting decision making and may be hampering the growth of the marine industry. For instance, one recent study (Chick and Laurence 2016) found a large number of challenges relating to data availability, discoverability, quality, confidentiality and ownership. It concluded that there is considerable scope for mapping services at a national level in New Zealand through greater collaboration between a wider range of disciplines and stakeholders - to support decision making. A recent example of information hampering decisions occurred in 2015 when Chatham Rock Phosphate (CRP) was denied a licence to mine phosphate nodules of the seabed off the Chatham Rise. The project was due to provide New Zealand with $\$ 900$ million in economic benefits (NZIER 2012). One reason cited for the denial was the level of uncertainty of the environmental impact from the mining itself and the sediment plumes created by it. Whilst CRP used the 'best available information' this fell short in some key areas (Environmental Protection Authority 2015, p. 210).

As shown by the studies here, Hydrographic departments have a role in data curation and are recently showing greater leadership in this area. This could be one place to start and MSDI in New Zealand given its strong, internationally recognised hydrographic department. However, this would only be a starting place and to produce a full MSDI would require a focused fully funded national programme such as Digital Coast, or EMODnet to fully realise the benefits of open, available marine data.

\section{Conclusions}

This paper sought to address the gap in published literature on the economic benefits of MSDIs. We used a quasi-systematic method to review and analyse eight studies that show cost-benefits for MSDIs and then create an aggregated view of their main trends and the demonstrated costs and benefits of MSDIs. We then looked at these results in the context of New Zealand's position. To summarise the main results :

MSDIs exist in a variety of arrangements. Some are involved in surveying and distributing data e.g. mainly those associated to a hydrographic service and others are purely data warehouses e.g. EMODnet, INSPIRE, focused data collation distribution. Each has various levels of impact in terms of economic and social benefits

All the studies in this review showed a net benefit of implementing an MSDI. Even using the conservative predictions on average this benefit was between 1:2 and 1:18 i.e. between two and eighteen dollars returned for every one put in.

The studies had differences in the methods they used to quantify costs and benefits and what was included in their calculations. Like many studies of this nature It is acknowledged that it is difficult to identify all the benefits, quantify them and express them in monetary terms. Even so there were some common themes between all the studies which demonstrated so consistency across this review. 
In all of the studies a key goal and benefit was open data allowing for more transactions with the same data. Lastly, in many of the studies the overall purported outcome was improved decision making, leading to better overall outcomes. For example, reduced population exposed to flooding.

This study has limitations. Many of the published reviews identified could be biased because they are seeking funding, rather than providing an objective view of MSDIs. Furthermore because of the lack of literature in this area some of the studies could be seen to be out of date, or not completely relevant. In particular many of the studies should have realised benefits by now, however most do not have follow up reviews to investigate the effectiveness of the programmes. The fact that this piece of research adjusts costs and benefits to present day and combines multiple pieces of research together should mitigate some of these limitations.

Lastly, future research could investigate the effectiveness of MSDI programmes by contacting the individual authors and agencies who wrote the original cost benefit analyses and evaluate how effective the programmes actually were compared to their projected benefits.

\section{References}

Bradbury, A.P., 2006. Strategic Regional Coastal Monitoring Programme for the Southwest -Phase 1 2007-2012, Channel Coastal Observatory.

Ache, C. M., and Victor, A., 2009. The Cost-Benefit of Charting Cameroon Waters, 7th FIG Regional Conference, Hanoi, October 19-22.

Australia New Zealand Land Information Council, 1996. Spatial Data Infrastructure for Australia and New Zealand - Discussion Paper, Australia New Zealand Land Information Council.

Australia New Zealand Land Information Council, 1995, Australian Land and Geographic Data Infrastructure Benefit Study, Australian Government Publishing Service, Canberra.

Barbera M., 2012. Towards an economic valuation of the Hauraki Gulf: a stock-take of activities and opportunities. Auckland Council technical report.

Brinkman, G.L., and Caverley, S. L., 1992. Benefit-Cost Assessment of the Canadian Hydrographic Service. Intercambio Limited, as yet unpublished

Cellini, S.R., and Kee, J.E., 2010. Cost-effectiveness and cost-benefit analysis. In: Kathryn E., et al, ed. Handbook of practical program evaluation, Wiley online library, 493.

Chick, A., Laurance R., 2016 Mapping the services and benefits of indigenous biodiversity and historic heritage in New Zealand An exploration of spatial datasets, Wellington, Department of Conservation.

Connon, B., and Nairn R., 2011. Economic Impact of Hydrographic Surveys, Report on the Economic Benefits of Hydrography. FIG Publication No 57 10-22.

Dufourmont, H., 2004. Extended Impact Assessment of INSPIRE based on revised scope. European Commission, DG Eurostat, Luxemburg. 
European Commission, 2007. Directive 2007/2/EC of the European Parliament and of the Council of 14 March 2007 establishing an Infrastructure for Spatial Information in the European Community (INSPIRE). Published in the official Journal on the 25th April.

European Commission, Commission Staff Working Document. 2010 European Marine Observation and Data Network IMPACT Assessment SEC (10) 998 final, Brussels, European Commission

Fowler, C., et al 2010. Building a marine spatial data infrastructure to support marine spatial planning in US waters. Available from: http://www.gislands.Org

Gajewski, et al 2012 comments to The Green Paper: Marine Knowledge 2020 by Maritime Institute in Gdansk, Poland available from:

http://ec.europa.eu/dgs/maritimeaffairs fisheries/consultations/marine-knowledge2020/index en.htm

Hoegh-Guldberg, O., 2015. Reviving the Ocean Economy: the case for action - 2015. World Wildlife Fund International, Gland, Switzerland., Geneva

INFOMAR. 2008. Marine mapping study options appraisal report: final report

PricewaterhouseCoopers. Available at:

http://www.infomar.ie/documents/INFOMAR\%200ptions\%20Appraisal\%20Report PwC.pdf

[Accessed 7 April 2017].

International Hydrographic Organization (IHO). 2011a. Spatial Data Infrastructures The marine dimension - Guidance for Hydrographic offices, Edition 1.1, international hydrographic Bureau, Monaco

International Hydrographic Organization (IHO). 2011b. The Need for National Hydrographic Services. IHO Publication M-2

Land Information New Zealand 2015 New Zealand Bathymetry Investigation Wellington, Land Information New Zealand. Available at: http://www.linz.govt.nz/about-linz/what-weredoing/projects/new-zealand-bathymetry-investigation [Accessed 7 April 2017].

Land Information New Zealand, 2012 New Zealand SDI State of Play Report 2012, Wellington, Land Information New Zealand. Available at: http://www.linz.govt.nz/about-linz/our-locationstrategy/geospatial-strategy-for-spatial-data-infrastructure/new-zealand-geospatial-strategy [Accessed 7 April 2017].

Leveson, I., 2012. Socio-Economic Study: Scoping the Value of NOAA's Coastal Mapping Program. cell 609: 462-3112. Available at: https://www.iho.int/iho pubs/misc/M 2 Suppldocs/2012-SocioEconomic Scoping Study NOAA.pdf [Accessed 7 April 2017].

MBeau Ache, C., et al, 2009. The Cost-Benefit of Charting Cameroon Waters, 7th FIG Regional Conference, Hanoi. Available at:

https://www.fig.net/resources/publications/figpub/pub57/pub57 article04.pdf [Accessed 7 April 2017]. 
National Oceanic and Atmospheric Administration (NOAA) Coastal Services Center. 2015. Projected Benefits and Costs of the Digital Coast. Charleston, SC: NOAA Coastal Services Center. Available at: https://coast.noaa.gov/data/docs/digitalcoast/benefits-costs.pdf [Accessed 7 April 2017].

NZ Institute of Economic Research. 2012. Economic assessment of Chatham Rock Phosphate. NZIER, Wellington

NZ Institute of Economic Research. 2012. Value of oil and gas exploration, Hypothetical scenarios. A report for the Economic Development Group at the Ministry of Business. NZIER, Wellington

Open Geospatial Consortium. 2015. The OGC helps make distributed responsibility for data a good policy http://www.opengeospatial.org/domain/gov and sdi\#responsibility

QinetiQ, Lloyd's Register, University of Strathclyde. 2013. Global Marine Trends 2030 London, Fourtwentyseven.

Secretariat of the Pacific Community. 2014. Assessing The Costs And Benefits Of Hydrographic Survey And Charting A Case Study Of Vanuatu, Secretariat of the Pacific Community.

Statistics New Zealand 2016. New Zealand's marine economy: 2007-13. Available at: http://www.stats.govt.nz/browse for stats/environment/environmental-economic-accounts/nzmarine-economy-2007-13.aspx [Accessed 7 April 2017].

Strain et al. 2006. Marine administration and spatial data infrastructure. Marine Policy 30.4: 431441.

Tasman, A.C.I.L. 2009. Spatial information in the New Zealand economy: realising productivity gains. prepared for Land Information New Zealand, pp.77-95.

The Cochrane Collaboration, 2008, Cochrane Handbook for Systematic Reviews of Interventions England, Wiley-Blackwell

Transportation Working Group. 2002. Analysis of the Economic Benefits of the Provision of Hydrographic Services in the APEC Region Transportation Working Group

Trapp, N., et al., 2015. A Meta-Analysis on the Return on Investment of Geospatial Data and Systems: A Multi-Country Perspective. Transactions in GIS, 19(2), 169-187.

UNCLOS. 1982. United Nations Convention on the Law of the Sea, Montego Bay, Jamaica. 